\title{
Avaliação do Comportamento Térmico por DSC na Região da Pele e do Núcleo de Amostras Injetadas de Nanocompósitos de Poliamida 6/Argila Organofílica
}

\author{
Renê A. da Paz, Amanda M. D. Leite \\ Departamento de Ciência e Engenharia de Materiais, UFCG
}

\author{
Edcleide M. Araújo, Tomas J. A. Melo \\ Departamento de Engenharia de Materiais, UFCG
}

\author{
Luiz A. Pessan \\ Departamento de Engenharia de Materiais, UFSCar
}

\begin{abstract}
Resumo: Nanocompósitos de poliamida 6/argila organofílica foram preparados pelo método de intercalação por fusão. A argila foi tratada com o sal quaternário de amônio (Cetremide) visando-se à obtenção da argila organofílica (OMMT). Esta foi caracterizada por fluorescência de raio X (FRX), Espectroscopia no Infravermelho (FTIR) e Difração de raio X (DRX). Os resultados dessas análises evidenciaram incorporação do sal entre as camadas da argila, tornando-a organofílica. Os nanocompósitos foram obtidos em extrusora de rosca dupla corrotacional, com 3\% em peso de argila, e estes foram posteriormente injetados. A caracterização dos nanocompósitos por DRX mostrou uma estrutura esfoliada e/ou parcialmente esfoliada. As análises por Calorimetria Exploratória Diferencial (DSC) foram realizadas nas regiões da pele (superfície) e do núcleo (centro) dos corpos de prova e, mostraram as fases cristalinas $\alpha$ e $\gamma$ na pele e apenas a fase $\alpha$ no núcleo e que o grau de cristalinidade na pele foi menor do que no núcleo.
\end{abstract}

Palavras-chave: Poliamida 6, argila organofílica, nanocompósitos, cristalização.

\section{Polyamide 6/0rganoclay Nanocomposites: Evaluation of Thermal Behavior of Injection Molded Samples by DSC}

\begin{abstract}
Polyamide 6/organoclay nanocomposites were prepared using the melt intercalation technique. The clay was treated with a quaternary ammonium salt (Cetremide) to obtain the organoclay (OMMT), which was characterized with X ray fluorescence (XRF), Infrared Spectroscopy (FTIR) and X ray diffraction (XRD). The results of these analyses showed the incorporation of the salt in the clay structure, confirming the organophilization. The nanocomposites were obtained in a co-rotational twin screw extruder with 3 wt. (\%) of clay, and then the pellets were injection molded. The characterization by XRD of the nanocomposites showed an exfoliated and/or partially exfoliated structure. The analysis by DSC were made in the skin and core regions of the samples, showing the $\alpha$ and $\gamma$-crystalline forms in the skin and only the $\alpha$-form in the core region. The degree of crystallinity in the skin was lower than in the core.
\end{abstract}

Keywords: Polyamide 6, organoclay, nanocomposites, crystallization.

\section{Introdução}

Nos últimos anos tem-se dado muita atenção aos materiais nanocompósitos de polímero/argila, principalmente aos nanocompósitos desenvolvidos com silicatos em camadas, devido à necessidade de materiais de engenharia mais eficientes e ao fato dos polímeros puros não apresentarem propriedades necessárias para determinadas aplicações. Vários métodos têm sido aplicados para preparação de nanocompósitos polímero/argila, dentre eles o mais utilizado é o de intercalação por fusão ${ }^{[1]}$.

Nanocompósitos poliméricos são materiais híbridos onde substâncias inorgânicas de dimensões nanométricas estão dispersas em uma matriz polimérica ${ }^{[2,3]}$. Os nanocompósitos polímero/silicato em camadas são comparados aos compósitos poliméricos convencionais, pois eles usam cargas para melhorar algumas propriedades específicas ${ }^{[1]}$. Tais nanocompósitos têm vantagens quando comparadas aos compósitos convencionais, pois apresentam melhoria nas propriedades mecânicas, térmicas, de inflamabilidade e estabilidade dimensional, utilizando baixos teores de silicato, entre $1-5 \%$ em peso $^{[4]}$.
A partir das pesquisas realizadas pelo grupo da Toyota que desenvolveu nanocompósitos de poliamida 6 com pequenas quantidades de argila montmorilonita e obtiveram para este sistema um aumento significativo das propriedades mecânicas e térmicas, vários outros estudos têm sido realizados a fim de se obter sinergia entre os componentes, dada à importância do desenvolvimento desse tipo de material ${ }^{[5,9-15,19-24]}$.

Os silicatos em camadas utilizados como cargas têm partículas com dimensões nanométricas (1-500 nm) e, portanto, eles apresentam uma área de superfície elevada o que promove melhor interação com a matriz polimérica e, por conseguinte, uma melhoria das propriedades físicas ${ }^{[5]}$. Uma variedade de polímeros tem sido usada na preparação de nanocompósitos polímero-argila tais como: poliestireno, poliamida 6 e 66 , policarbonato, poliolefinas, etc. ${ }^{[6]}$. $\mathrm{O}$ efeito da presença dos silicatos em camadas e o nível de esfoliação destes na estrutura cristalina de matrizes poliméricas têm sido estudados e tem-se observado que eles afetam o comportamento cristalino e, consequentemente, as propriedades físicas e

Autor para correspondência: Edcleide M. Araújo, Departamento de Engenharia de Materiais, Universidade Federal de Campina Grande,

Av. Aprígio Veloso, 882, CEP: 58109-970, Campina Grande, PB, Brasil. E-mail: edcleide@dema.ufcg.edu.br 
mecânicas. Nanocompósitos de poliamida6/argila organofílica foram estudados por Fornes et al. ${ }^{[8]}$. Eles analisaram a estrutura cristalina das amostras por meio de DSC e DRX e observaram que a argila influencia no grau de cristalinidade da pele e do núcleo das amostras. Vários estudos vêm sendo realizados, focados no comportamento de cristalização destes materiais ${ }^{[8-10]}$. O objetivo desse trabalho foi avaliar o comportamento térmico de regiões da pele (superfície) e do núcleo (centro) de amostras extraídas de corpos de prova injetados de nanocompósitos de poliamida 6 com argila bentonítica organofílica.

\section{Experimental}

\section{Materiais}

Argila Bentonítica Brasgel PA (sódica), CTC (capacidade de troca catiônica $)=90 \mathrm{meq} / 100 \mathrm{~g}$ (método de adsorção de azul de metileno), passada em peneira ABNT no $200(\mathrm{D}=74 \mu \mathrm{m})$, de cor creme, fornecida pela Bentonit União Nordeste (BUN), localizada na cidade de Campina Grande, PB. A argila foi denominada de argila sem tratamento (MMT), devido ao argilomineral predominante ser a montmorilonita. Para torná-la compatível com a matriz polimérica, os íons de sódio presentes entre as lamelas da argila são trocados por íons de amônio para produzir a argila organofílica, denominada de OMMT. Essa troca foi realizada na presença do sal quaternário de amônio Cetremide (Brometo de hexadeciltrimetil amônio), fornecido pela Vetec/SP. Para a obtenção da argila organofílica (OMMT) foi realizado tratamento apropriado para o sal, baseando-se na CTC da argila, conforme procedimento reportado em trabalhos anteriores ${ }^{[2,6,7]}$.

A matriz polimérica empregada foi a poliamida 6 (Technyl C216) fornecida pela Rhodia/SP, sob a forma de grânulos de coloração branca. Antes de qualquer etapa de processamento, todos os materiais contendo poliamida foram secados em estufa a vácuo a $80{ }^{\circ} \mathrm{C}$ por 24 horas.

\section{Métodos}

Para a produção dos nanocompósitos da poliamida foi preparado um concentrado (1:1) em misturador interno acoplado ao Reômetro de Torque System 90 da Haake-Büchler, operando-se a $240{ }^{\circ} \mathrm{C}$, $60 \mathrm{rpm}$ por 10 minutos. O concentrado obtido foi triturado em moinho de facas e, posteriormente, adicionado à matriz polimérica, em quantidades necessárias para a obtenção de teores nominais de $3 \%$ em massa de argila.

A mistura poliamida 6/argila organofílica foi processada em extrusora de rosca dupla corrotacional Werner-Pfleiderer ZSK 30, utilizando-se temperatura de $220^{\circ} \mathrm{C}$ na $1^{\text {a }}$ zona e $240{ }^{\circ} \mathrm{C}$ nas demais zonas de aquecimento. A velocidade de rotação das roscas foi de 100 e $200 \mathrm{rpm}$ e taxas de alimentação de 5 e $10 \mathrm{~kg} / \mathrm{h}$ e dois perfis de rosca R1 e R2. As roscas são compostas de vários elementos de transporte, porém a diferença entre elas está na zona de mistura, ou seja, na rosca $\mathrm{R} 1$ esta zona apresenta apenas um bloco com elementos de malaxagem, seguido por um elemento de passo esquerdo e, na rosca R2 dois blocos com elementos de malaxagem seguido por um elemento de passo esquerdo. Para efeito de comparação, a poliamida 6 pura foi extrudada sob as mesmas condições de mistura, com taxa de alimentação de $5 \mathrm{~kg} / \mathrm{h}$. As amostras foram assim nomeadas: 5100R1, que significa: taxa de alimentação de $5 \mathrm{~kg} / \mathrm{h}$, velocidade de $100 \mathrm{rpm}$ e rosca $\mathrm{R} 1$. As demais amostras seguem o mesmo padrão de nomeação. As alterações de velocidade de rotação, dos perfis de rosca e taxas de alimentação foram realizadas a fim de se avaliar o efeito destas variáveis de processamento na estrutura e no comportamento térmico dos nanocompósitos de poliamida 6 obtidos.

\section{Caracterizações}

A argila organofílica obtida conforme procedimento reportado em trabalhos anteriores ${ }^{[2,4,6,7]}$ foi caracterizada por DRX, FRX e FTIR e os nanocompósitos caracterizados por DRX e DSC, para que fosse determinado o espaçamento basal entre as camadas de argila e sua composição química, bem como verificar a formação do nanocompósito. As análises de DRX foram realizadas em aparelho XRD-6000 Shimadzu, utilizando-se radiação K $\alpha$ do cobre $(\lambda=1,542 \AA)$, tensão de $40 \mathrm{kV}$, corrente de $30 \mathrm{~mA}$, varredura entre $2 \theta$ de 2 a $30^{\circ}$ e velocidade de varredura de $2{ }^{\circ} \mathrm{C} / \mathrm{min}$. A análise por Fluorescência de raio $\mathrm{X}$ da argila foi realizada pelo método semiquantitativo, em forma de pastilha, sob atmosfera de nitrogênio, em equipamento modelo EDX 700 da Shimadzu. A Espectroscopia por Infravermelho foi realizada em um espectrômetro Spectrum 400 Perkin Elmer FT-IR/FT-NIR Spectrometer com varredura de 4000 a $650 \mathrm{~cm}^{-1}$. O equipamento não requer preparo das amostras (a leitura é direta para as argilas) e a quantidade não é padronizada.

O comportamento não isotérmico de cristalização usando aquecimento e resfriamento de amostras retiradas dos corpos de prova da poliamida 6 e seus nanocompósitos foi avaliado usando um DSC 7 da Perkin-Elmer. Os corpos de prova foram secados sob vácuo, por aproximadamente 24 horas a $80^{\circ} \mathrm{C}$ antes da análise térmica. Foram utilizadas em torno de $8 \mathrm{mg}$ de amostras retiradas dos corpos de prova, em profundidades de 0,2 e $1,5 \mathrm{~mm}$, correspondente às regiões da pele (superfície) e do núcleo (centro), respectivamente. As amostras foram aquecidas a uma taxa de aquecimento de $10^{\circ} \mathrm{C} / \mathrm{min}$, da temperatura ambiente até $260^{\circ} \mathrm{C}$, e mantidas em isoterma por 1 minuto na temperatura de $260{ }^{\circ} \mathrm{C}$. As amostras foram resfriadas e novamente aquecidas para se avaliar os efeitos do resfriamento. As seguintes variáveis foram analisadas: temperatura de fusão cristalina $(\mathrm{Tm})$, calor de fusão $(\Delta \mathrm{Hf})$ e temperatura de cristalização $(\mathrm{Tc})$.

\section{Resultados e Discussão}

\section{Caracterização da argila}

A Figura 1 apresenta os difratogramas de DRX das argilas, MMT e OMMT. Comparando-se os difratogramas, pode-se visualizar que houve um deslocamento do ângulo $2 \theta$ de 7,3 $\left(\mathrm{MMT}\right.$ ) para $4,06^{\circ}$ (OMMT), ou seja, aplicando-se a Lei de Bragg, a distância basal, $\mathrm{d}_{001}$, passou de $12,81 \AA$ para $21,34 \AA$ respectivamente. Isto indica que houve a intercalação das moléculas do sal entre as camadas da argila, conforme visualizado no trabalho por Barbosa ${ }^{[4]}$ que também utilizou este sal quaternário de amônio na organofilização de argilas bentoníticas de mesma procedência.

A técnica de Fluorescência de raio X foi utilizada para verificar a composição química da argila, mostrada na Tabela 1. Observa-se a presença de bromo na argila modificada com Cetremide (OMMT), bem como, a ausência do sódio nesta argila. Estes resultados evidenciam a eficiência da troca de cátions ocorrida entre o sal quaternário e a argila, indicando a presença do cátion quaternário de amônio nos espaços interlamelares da argila.

\section{Espectroscopia no infravermelho (FTIR)}

A Figura 2 apresenta os espectros no infravermelho obtidos para a argila sem tratamento (MMT) e para a argila organofílica (OMMT). Na argila organofílica (OMMT), observam-se novas bandas características do sal utilizado, na faixa de $2.920 \mathrm{~cm}^{-1}$ que correspondem às vibrações de estiramento assimétrico e simétrico do grupo $\mathrm{CH}_{2}$ e em aproximadamente $1.490 \mathrm{~cm}^{-1}$, às vibrações de flexão dos grupos $\mathrm{CH}_{3}$ Isto confirma a presença das moléculas do sal na argila, estando de acordo com os resultados de Barbosa ${ }^{[2]}$. 
Observa-se a presença de hidroxilas da argila em 3.600 a $3.500 \mathrm{~cm}^{-1}$. Em $1.650 \mathrm{~cm}^{-1}$, banda característica de água adsorvida; entre 1.000 e $800 \mathrm{~cm}^{-1}$, banda característica de ligações Si-O-Si e na faixa de 780 a $670 \mathrm{~cm}^{-1}$, banda característica da camada octaédrica para a argila sem tratamento (MMT) e para a argila organofílica (OMMT). De acordo com Kozak \& Domka, citados por Barbosa ${ }^{[4]}$, por meio dessa análise fica evidenciada a presença das moléculas do sal na argila modificada.

\section{Caracterização dos nanocompósitos}

\section{Difração de raio $X(D R X)$}

Para a avaliação da formação dos nanocompósitos de poliamida 6/argila organofílica, os sistemas foram caracterizados por DRX, pois esta técnica possibilita determinar o espaçamento basal $\left(\mathrm{d}_{001}\right)$ entre as camadas da argila.

A Figura 3 apresenta os difratogramas de raio $X$ da poliamida 6 (PA6) e dos sistemas PA6/argila organofílica (OMMT), analisados por meio dos corpos de prova de tração obtidos por injeção. Para efeito de comparação, é também mostrado o DRX da argila OMMT. Percebe-se que o pico da argila organofílica com $d_{001}=21,34 \AA$ desapareceu quando esta foi incorporada nas matrizes de poliamida 6

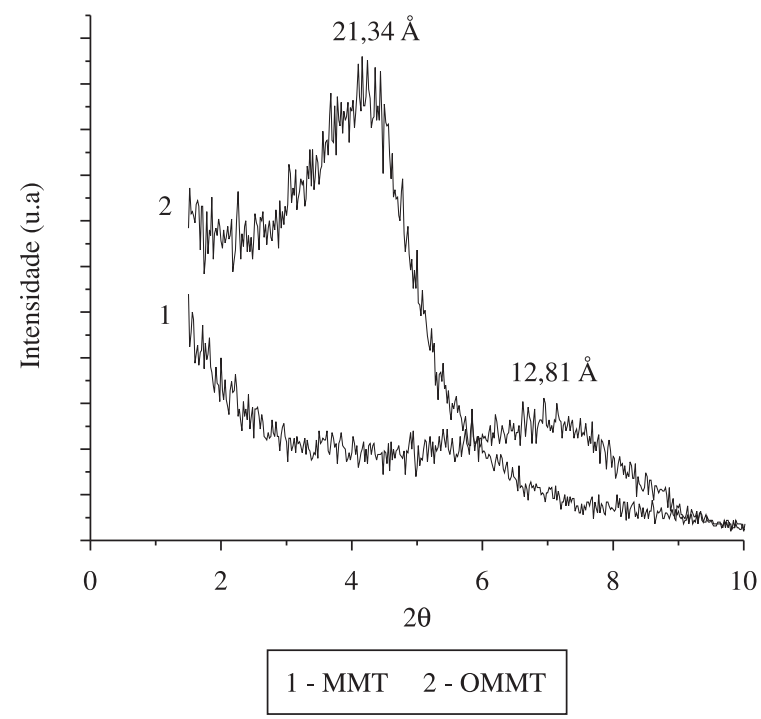

Figura 1. Difratograma da argila sem tratamento (MMT) e da argila organofílica (OMMT).

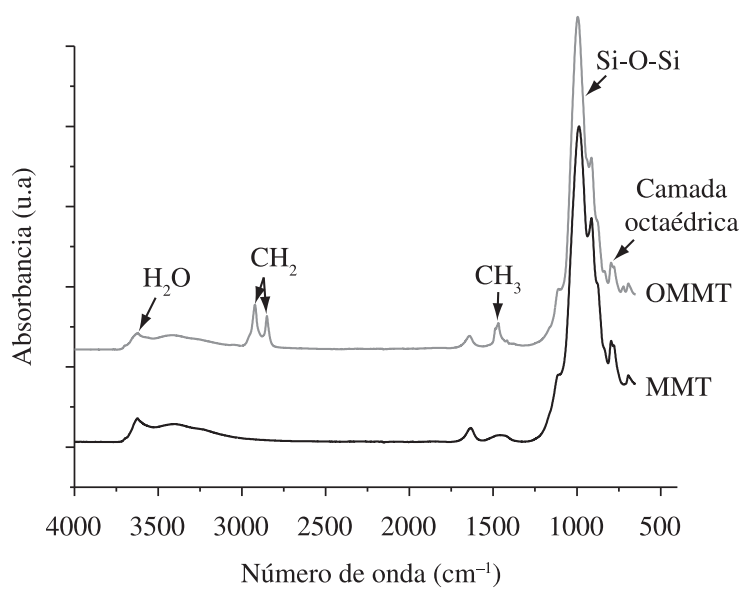

Figura 2. Espectros de FTIR obtidos para a argila sem tratamento (MMT) e para a argila organofílica (OMMT). e, apareceu um pico em torno de $2 \theta=21^{\circ}$. Esses resultados de DRX podem indicar que todos os sistemas apresentam estrutura esfoliada e/ou parcialmente esfoliada, de acordo com outros resultados encontrados na literatura ${ }^{[6,7,16]}$. É interessante destacar que as curvas dos nanocompósitos apresentam o mesmo comportamento, independentemente, da velocidade de rotação, dos perfis de rosca e das taxas de alimentação utilizados. Esta observação reforça a argumentação de que nanocompósitos obtidos a partir de polímeros funcionalizados ou polares, do tipo poliamidas, com silicatos em camadas tendem a apresentar estrutura esfoliada e/ou parcialmente esfoliada, independentemente das condições de processamento a que foram submetidos. O que não ocorre para os polímeros apolares, onde se faz necessário o uso de compatibilizantes e equipamentos

Tabela 1. Composição química da argila sem tratamento (MMT) e da argila organofílica (OMMT) obtida por meio da técnica de fluorescência de raio $\mathrm{X}$.

\begin{tabular}{ccc}
\hline Determinações (\%) & MMT & OMMT \\
\hline $\mathrm{SiO}_{2}$ & 62,693 & 61,718 \\
$\mathrm{Al}_{2} \mathrm{O}_{3}$ & 19,593 & 21,191 \\
$\mathrm{Fe}_{2} \mathrm{O}_{3}$ & 9,314 & 9,882 \\
$\mathrm{MgO}$ & 3,180 & 2,914 \\
$\mathrm{Na} \mathrm{O}_{2}$ & 1,801 & - \\
$\mathrm{CaO}$ & 1,617 & 1,004 \\
$\mathrm{TiO}_{2}$ & 0,912 & 1,000 \\
$\mathrm{~K}_{2} \mathrm{O}$ & 0,523 & 0,579 \\
$\mathrm{Br}$ & - & 1,067 \\
$\mathrm{RuO}_{2}$ & 0,220 & 0,334 \\
$\mathrm{SO}_{3}$ & - & 0,124 \\
$\mathrm{MnO}$ & 0,052 & 0,063 \\
$\mathrm{Rb}_{2} \mathrm{O}$ & - & 0,053 \\
$\mathrm{~V}_{2} \mathrm{O}_{5}$ & 0,041 & 0,036 \\
$\mathrm{Cr}_{2} \mathrm{O}_{3}$ & 0,026 & 0,024 \\
$\mathrm{SrO}_{\mathrm{ZnO}}$ & 0,014 & 0,011 \\
$\mathrm{Y}_{2} \mathrm{O}_{3}$ & 0,010 & - \\
& 0,005 & - \\
\hline
\end{tabular}

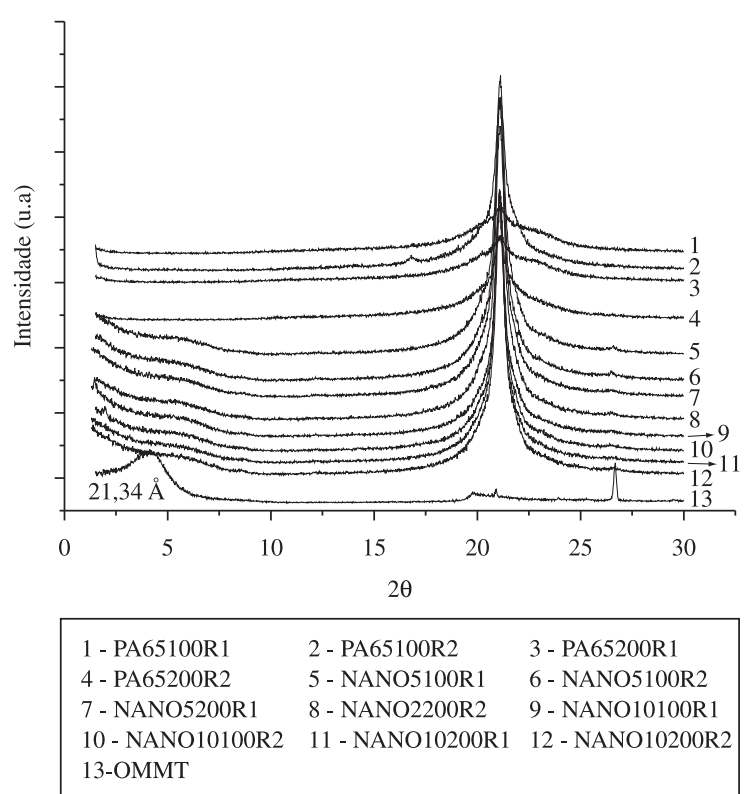

Figura 3. Difratogramas da poliamida 6 e seus nanocompósitos. 


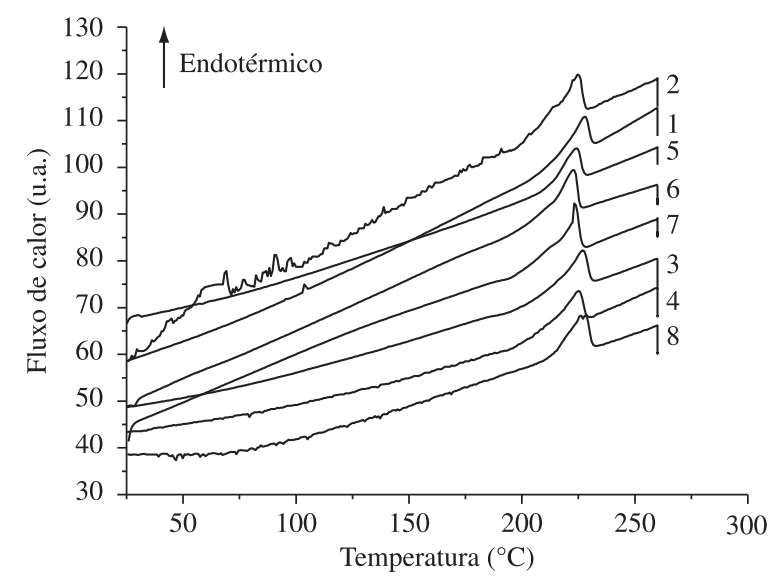

(a)

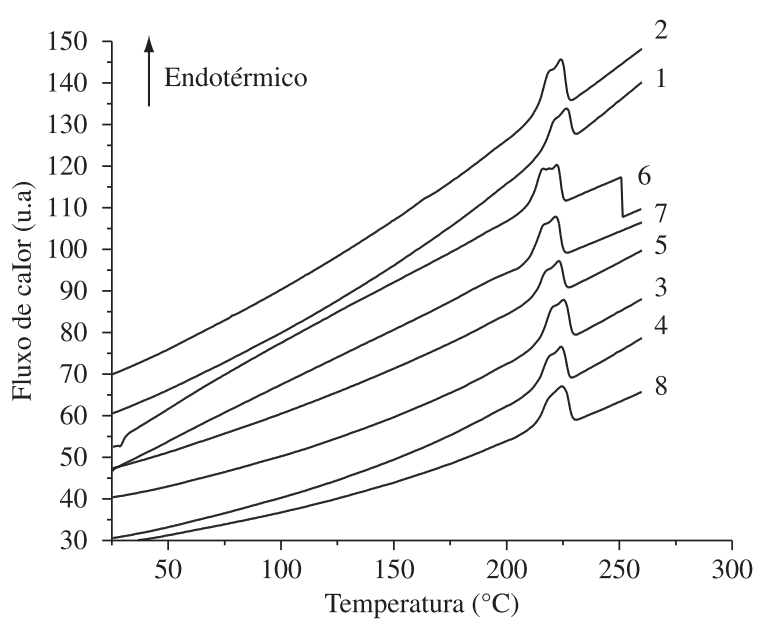

(b)

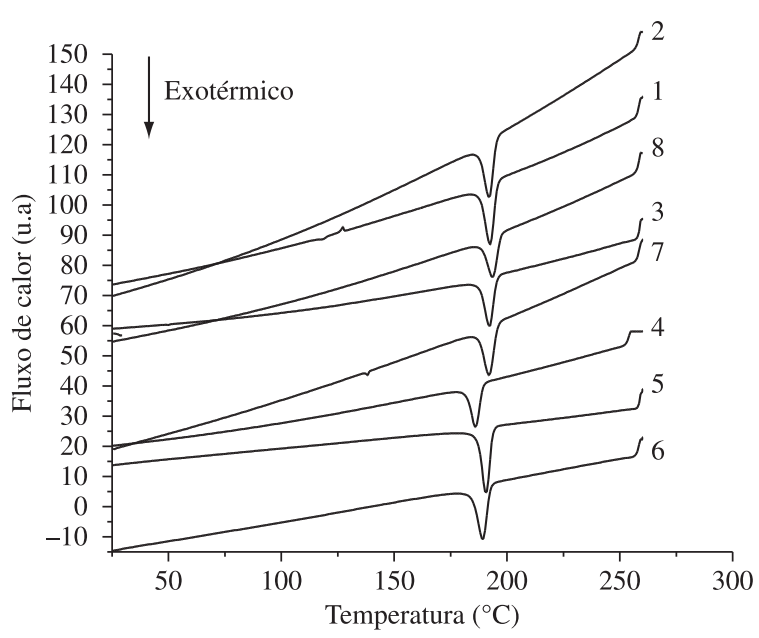

(c)

Figura 4. Termogramas de DSC da região da pele de amostras moldadas por injeção de poliamida 6 e seus nanocompósitos: a) $1^{\circ}$ aquecimento; b) $2^{\circ}$ aquecimento; e c) resfriamento.

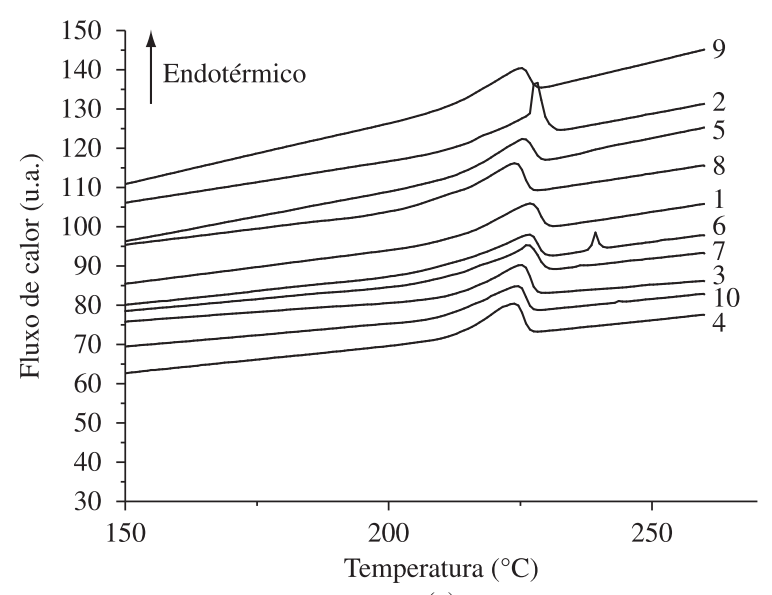

(a)

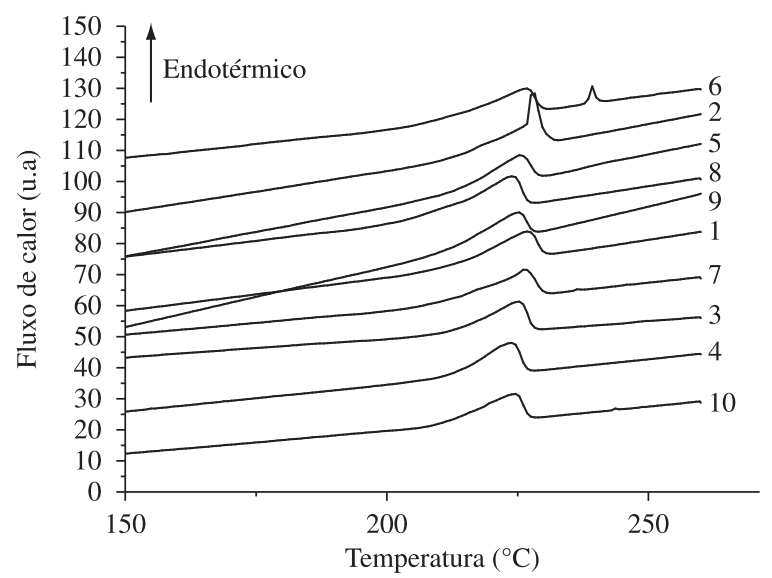

(b)

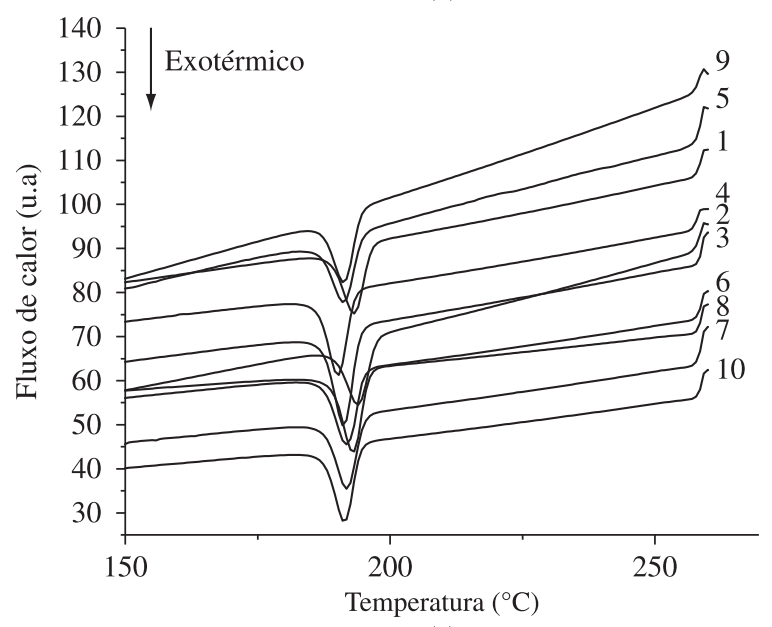

(c)

\begin{tabular}{|lll|}
\hline 1 - PA65100R1 & 2 - PA65100R2 & 3 - PA65200R2 \\
4 - NANO5100R1 & 5 - NANO5100R2 & 6 - NANO5200R2 \\
7 - NANO10100R1 & 8 - NANO10100R2 & 9 - NANO10200R1 \\
10 - NANO10200R2 & & \\
\hline
\end{tabular}

Figura 5. Termogramas de DSC da região do núcleo de amostras moldadas por injeção de poliamida 6 e de seus nanocompósitos: a) $1^{\circ}$ aquecimento; b) $2^{\circ}$ aquecimento; e c) resfriamento. 
de processamento adequados, a fim de se obter nanocompósitos intercalados e/ou parcialmente esfoliados. Estes resultados foram confirmados por meio de vários trabalhos já desenvolvidos e $\operatorname{apresentados}^{[6,16-18]}$.

\section{Calorimetria exploratória diferencial (DSC)}

É importante entender como a presença de argila e o nível de esfoliação desta afeta o grau de cristalinidade na poliamida, pois a estrutura cristalina resultante influenciará nas propriedades físicas e mecânicas dos nanocompósitos. Muitas das propriedades melhoradas dos nanocompósitos com poliamida 6 , podem ser explicadas pela esfoliação e dispersão das camadas da argila na matriz polimérica, mas alguns efeitos nessas propriedades podem estar relacionados à modificação cristalina do polímero pela argila ${ }^{[8-10]}$.

No processo de moldagem por injeção, a temperatura em que o molde é mantido é uma variável importante do processo, em especial para polímeros semi-cristalinos, pois controla o processo de cristalização. Além da temperatura, as tensões de cisalhamento impostas ao polímero fundido causadas por injeção rápida é um fator importante no processo de cristalização. Alto nível de tensão, particularmente na superfície do molde, faz com que as cadeias de polímero se alinhem na direção do fluxo, facilitando assim a cristalização. Geralmente, a região da pele sofre resfriamento mais rápido mantendo um grau de orientação maior, enquanto a região do núcleo da peça moldada resfria mais lentamente e sofre menos tensão, o que produz uma estrutura pele-núcleo diferenciada. Esta diferença em termos de propriedades físicas e mecânicas pode ser significativa. Em termoplásticos semicristalinos, a pele e o núcleo diferem tanto na cristalização quanto na orientação da matriz polimérica e, portanto, os efeitos da pele e do núcleo devem ser considerados na injeção ao projetar peças moldadas ${ }^{[8]}$.

Estudos de cristalização não isotérmica foram realizados por aquecimento a uma taxa de $10{ }^{\circ} \mathrm{C} / \mathrm{min}$ até $260{ }^{\circ} \mathrm{C}$ e mantidos em isoterma por 1 minuto, antes do resfriamento. A Figura $4 \mathrm{a}, \mathrm{b}$ e c, e a Figura 5a, b e c, apresentam as curvas de DSC das regiões da pele e do núcleo, respectivamente, de amostras retiradas de corpos de prova moldados por injeção de PA6 e de seus nanocompósitos. As Tabelas 2 e 3 resumem os dados obtidos por estes termogramas. De acordo com os dados, os sistemas em geral, apresentam variações, ou seja, mostram mudanças no formato do pico de fusão e cristalização em comparação com a poliamida 6 . Aparentemente, a presença da argila alterou o comportamento cristalino da poliamida, deixando o pico de fusão do nanocompósito mais largo para a região da pele e diminuindo a temperatura no pico (fusão e cristalização) e o grau de cristalinidade. Conforme sugerem Fornes e Paul ${ }^{[8]}$, isto pode ser atribuído à formação de um pequeno ombro antes do pico endotérmico que pode estar associado à forma cristalina $\gamma$ da poliamida 6 . Outros autores ainda defendem que estas alterações ocorrem devido a mudanças na espessura e distribuição dos cristalitos ${ }^{[10-12]}$. É como se as lamelas da argila impedissem os domínios cristalinos de se formarem, devido às restrições impostas às cadeias poliméricas, o que conduz a menores estruturas de cristalitos e mais defeitos nas lamelas cristalinas do polímero e, consequentemente, menores pontos de fusão. É interessante mencionar ainda que maiores alterações no pico de fusão foram observadas para a região da pele e no $2^{\circ}$ aquecimento, ou seja, provavelmente a região da pele apresenta as duas formas cristalinas da poliamida 6 , as formas $\alpha$ e $\gamma$. Já a região do núcleo apresenta apenas a forma $\alpha$. Isto reforça a argumentação acima de que as diferenças na estrutura da pele e do

Tabela 2. Dados de DSC da região da pele de amostras moldadas por injeção de poliamida 6 e seus nanocompósitos.

\begin{tabular}{|c|c|c|c|c|c|c|}
\hline \multirow[t]{2}{*}{ Amostras } & \multicolumn{2}{|c|}{$1^{\circ}$ Aquecimento } & \multicolumn{2}{|c|}{ Resfriamento } & \multicolumn{2}{|c|}{$2^{\circ}$ Aquecimento } \\
\hline & $\mathbf{T}_{\mathrm{m}}\left({ }^{\circ} \mathbf{C}\right)$ & $\mathrm{X}_{\mathrm{c}}(\%)$ & $\mathbf{T}_{\mathrm{c}}\left({ }^{\circ} \mathrm{C}\right)$ & $\Delta \mathbf{H}_{\mathrm{c}}\left(\mathrm{J}_{\mathrm{g}} \mathrm{g}^{-1}\right)$ & $\mathbf{T}_{\mathrm{m}}\left({ }^{\circ} \mathbf{C}\right)$ & $\mathrm{X}_{\mathrm{c}}(\%)$ \\
\hline PA6 5100R1 & 227,5 & 22,5 & 193,6 & 41,5 & 226,0 & 17,1 \\
\hline PA6 5100R2 & 224,6 & 36,8 & 192,4 & 54,8 & 223,9 & 23,6 \\
\hline PA6 5200R2 & 226,7 & 17,8 & 193,4 & 48,7 & 225,0 & 14,0 \\
\hline NANO 5100R1 & 225,0 & 9,9 & 192,0 & 48,3 & 223,7 & 17,8 \\
\hline NANO 5100R2 & 224,8 & 8,7 & 192,2 & 46,9 & 223,9 & 19,1 \\
\hline NANO 5200R2 & 223,6 & 11,6 & 191,4 & 46,6 & 222,6 & 17,3 \\
\hline NANO10100R1 & 223,4 & 30,1 & 189,2 & 52,6 & 221,5 & 22,5 \\
\hline NANO10100R2 & 222,5 & 35,3 & 190,6 & 58,2 & 216,0 & 27,1 \\
\hline NANO10200R1 & 223,6 & 20,2 & 189,2 & 53,3 & 221,5 & 21,3 \\
\hline NANO10200R2 & 225,9 & 18,4 & 192,0 & 53,0 & 224,2 & 22,2 \\
\hline
\end{tabular}

$\mathrm{O}$ grau de cristalinidade $\left(\mathrm{X}_{\mathrm{c}}\right)$ foi calculado por $\Delta \mathrm{H}_{\mathrm{t}} / \Delta \mathrm{H}_{\mathrm{f} 100 \%}$, onde $\Delta \mathrm{H}_{\mathrm{f} 100}$ é a entalpia de fusão da PA6, $100 \%$ cristalina, ou seja, $188 \mathrm{~J} . \mathrm{g}^{-1[15]}$; os valores de entalpia foram normalizados em relação à PA6 pura.

Tabela 3. Dados de DSC da região do núcleo de amostras moldadas por injeção de poliamida 6 e seus nanocompósitos.

\begin{tabular}{|c|c|c|c|c|c|c|}
\hline \multirow[t]{2}{*}{ Amostras } & \multicolumn{2}{|c|}{$\mathbf{1}^{\circ}$ Aquecimento } & \multicolumn{2}{|c|}{ Resfriamento } & \multicolumn{2}{|c|}{$2^{\circ}$ Aquecimento } \\
\hline & $\mathbf{T}_{\mathrm{m}}\left({ }^{\circ} \mathbf{C}\right)$ & $\mathbf{X}_{\mathrm{c}}(\%)$ & $\mathbf{T}_{\mathrm{c}}\left({ }^{\circ} \mathbf{C}\right)$ & $\Delta \mathbf{H}_{\mathrm{c}}\left(\mathrm{J} \mathrm{g}^{-1}\right)$ & $\mathbf{T}_{\mathrm{m}}\left({ }^{\circ} \mathrm{C}\right)$ & $X_{c}(\%)$ \\
\hline PA6 5100R1 & 226,5 & 31,0 & 193,1 & 58,3 & 225,0 & 26,0 \\
\hline PA6 5200R2 & 225,0 & 29,0 & 192,9 & 58,5 & 224,4 & 23,3 \\
\hline NANO 5100R1 & 223,5 & 29,8 & 190,8 & 55,8 & 222,3 & 22,6 \\
\hline NANO 5100R2 & 226,5 & 25,0 & 191,7 & 56,1 & 223,5 & 22,9 \\
\hline NANO 5200R2 & 231,6 & 12,6 & 197,2 & 46,2 & 231,0 & 14,4 \\
\hline NANO10100R1 & 226,2 & 30,4 & 191,7 & 53,5 & 224,1 & 24,3 \\
\hline NANO10100R2 & 223,6 & 34,2 & 191,2 & 64,8 & 223,0 & 29,5 \\
\hline NANO10200R1 & 224,8 & 26,3 & 191,2 & 51,2 & 223,6 & 22,0 \\
\hline NANO10200R2 & 224,2 & 30,7 & 191,3 & 55,5 & 222,8 & 24,3 \\
\hline
\end{tabular}


núcleo nos polímeros devem ser consideradas. Em geral, o grau de cristalinidade da região do núcleo apresentou valores maiores do que a região da pele, tanto para as matrizes puras quanto para seus nanocompósitos.

\section{Conclusões}

Nanocompósitos de poliamida 6 com argila organofílica foram obtidos por intercalação por fusão. Por meio das técnicas de difração de raio $X$, FTIR e fluorescência de raio $X$ foi confirmada a presença das moléculas do sal quaternário de amônio na argila. Os resultados de DSC revelaram a presença das fases $\alpha$ e $\gamma$ na região da pele da PA6 e seus nanocompósitos e, apenas a fase $\alpha$ na região do núcleo. Foram verificadas também por DSC, variações de temperatura e entalpia de fusão, ou seja, mudanças no formato do pico de fusão em comparação com a poliamida 6 e que o grau de cristalinidade na região da pele foi menor em relação à região do núcleo para os nanocompósitos.

\section{Agradecimentos}

Os autores agradecem à Rhodia/SP pela doação da poliamida, Bentonit União Nordeste (BUN) pela doação da argila, ao DEMa/ UFCG e ao DEMa/UFSCar pelo uso de seus laboratórios, à CAPES/ PROCAD/NF, ao MCT/CNPq e à RENAMI, pelo apoio financeiro.

\section{Referências Bibliográficas}

1. Ganguli, S.; Dean, D.; Jordan, K.; Price, G. \& Vaia, R. - Polymer, 44, p.1315 (2003).

2. Barbosa, R.; Araújo, E. M.; Maia, L.; Pereira, O. D. F. \& Melo, T. J. A. - Polímeros, 16, 3, p.246 (2006).

3. Araújo, S. S.; Paiva, G. P.; Carvalho, L. H. \& Silva, S. M. L. - Rev. Mat., 9, p.426 (2004).

4. Barbosa, R.; Araújo, E. M.; Oliveira, A. D. \& Melo, T. J. A. - Cerâmica, 52, p.264 (2006).

5. Sinha Ray, S.; Okamoto, M. - Prog. Polym. Sci., 28, p.1539 (2003).

6. Paz, R. A. - "Efeito do Peso Molecular da Poliamida 6 no Desenvolvimento de Nanocompósitos", Dissertação de Mestrado, Universidade Federal de Campina Grande, Brasil (2008).

7. Araújo E. M.; Barbosa R; Rodrigues, A. W. B. \& Ito, E. N. - Mat. Sci. Eng. A, 141, p.445 (2007)
8. Fornes, T. D.; Paul, D. R. - Polymer, 44, p.3945 (2003).

9. Leszczy'Nska, A.; Njuguna, J.; Pielichowski, K. \& Banerjee, J. R. Therm Acta, 454, p.1 (2007).

10. Rodríguez, A. Y.; Alvarez-Lloret, P.; Cardell, C. \& Rodríguez-Navarro, A. B. Appl. Clay Sci., 43, p.91 (2009).

11. Fornes, T. D.; Yoon, P. J.; Keskkula, H. \& Paul, D. R. - Polymer, 42, p.9929 (2001).

12. Chiu, F. C.; Lai, S. M.; Chen, Y. L. \& Lee T. H. - Polymer, 46, p.11600 (2005).

13. Yuan, M.; Turng, L. S.; Gong, S. \& Winardi, A. - J. Cell Plast., 40, p.397 (2004).

14. Ozdilek, C. O.; Kazimierczak, K. \& Picken, S. J. - Polymer, 46, p.6025 (2005).

15. Leite, A. M. D.; Araújo, E. M.; Lira, H. L.; Barbosa, R. \& Ito, E. N. Polímeros, 19, p.271 (2009).

16. Paz, R. A.; Leite, A. M. D.; Araújo, E. M.; Melo, T. J. A.; Barbosa, R. \& Ito, E. N. - Polímeros, 18, p.341 (2008).

17. Leite, A. M. D.; Araujo, E. M.; Paz, R. A.; Pereira, O. D.; Lira, H. L. \& Ito, E. N. Mat. Res., 12, p.165 (2009).

18. Paz, R. A.; Araújo, E. M.; Melo, T. J.A.; Pereira, O. D. \& Barbosa, R. - REMAP- Rev. Elet Mat. Proce., 5, p.08 (2007).

19. Brito, G. F.; Oliveira, A. D.; Araújo, E. M.; Melo, T. J. A.; Barbosa, R.; Ito, E. N. - Polímeros, 18, p.170 (2008).

20. Medeiros, V. N.; Araújo, E. M.; Maia, L. F.; Pereira, O. D.; Arimateia, R. R. \& Paz, R. A. - Polímeros, 18, p. 302 (2008).

21. Neto, J. R. A.; Carvalho, L. H.; Araújo, E. M. - Polímeros, 17, p.10 (2007).

22. Barbosa, R.; Araújo, E. M.; Melo, T. J. A. \& Ito, E. N. Polímeros, 17, p.104 (2007).

23. Rodrigues, A. W. B.; Brasileiro, M. I.; Araújo, W. D.; Araújo, E. M.; Neves, G. A. \& Melo, T. J. A. - Polímeros, 17, p.219 (2007).

24. Araújo. E. M.; Oliveira, A. D.; Araujo, H. L. D.; Araújo, K. D.; Barbosa, R. \& Melo, T. J. A. - Polímeros, 16, 1, p.38 (2006).

Enviado: 04/12/09

Reenviado: 07/03/10

Aceito: $19 / 04 / 10$

DOI: $10.1590 / \mathrm{S} 0104-14282010005000043$ 